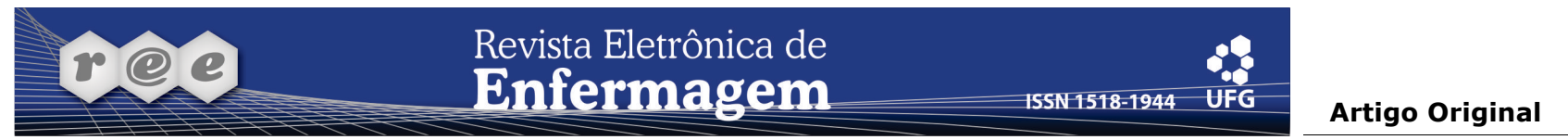

\title{
Mulheres que geram filhos expostos ao vírus da imunodeficiência humana: representações sociais da maternidade
}

Women who bear children exposed to human immunodeficiency virus: social representations of motherhood

Mujeres que engendran hijos expuestos al virus de inmunodeficiencia humana:

representaciones sociales de la maternidad

Marli Teresinha Gimeniz Galvão ${ }^{1}$, Gilmara Holanda da Cunha², Ivana Cristina Vieira de Lima ${ }^{3}$

${ }^{1}$ Enfermeira, Doutora em Doenças Tropicais. Professora Associada da Faculdade de Farmácia, Odontologia e Enfermagem da Universidade Federal do Ceará (FFOE/UFC). Fortaleza, CE, Brasil. E-mail: marligalvao@gmail.com.

${ }^{2}$ Enfermeira, Doutora em Enfermagem. Professora Adjunta da FFOE/UFC. Fortaleza, CE, Brasil. E-mail: gilmaraholandaufc@yahoo.com.br.

${ }^{3}$ Enfermeira, Mestre em Enfermagem. Fortaleza, CE, Brasil. E-mail: ivanacristinalima@gmail.com.

\section{RESUMO}

Estudo descritivo e qualitativo cujo objetivo foi identificar as representações sociais da maternidade de mulheres que geram filhos expostos ao vírus da imunodeficiência humana (HIV). Pesquisa realizada entre fevereiro e março de 2011, em hospital de referência no atendimento a pessoas com HIV, com inclusão de dez mães biológicas com pelo menos um filho nascido exposto ao vírus. Na coleta de dados, utilizou-se entrevista semiestruturada. A análise dos depoimentos determinou as categorias: culpa e medo de gerar um filho portador do HIV; discriminação e ocultação de ser portador do HIV; superproteção do filho; falta de apoio familiar; religiosidade como forma de enfrentamento. As representações sociais das mulheres foi uma organização de significados que funcionou como sistema de interpretação da realidade, regendo as relações com o meio físico e social, determinando comportamentos e práticas. Ademais, há necessidade de assistência em saúde qualificada e rede social de apoio para a promoção da saúde.

Descritores: HIV; Saúde da Mulher; Cuidados de Enfermagem.

\section{ABSTRACT}

Descriptive and qualitative study aimed to identify the social representations of motherhood in women bearing children exposed to the human immunodeficiency virus (HIV). Performed between February and March 2011 in a hospital considered a benchmark in caring for people with HIV, with ten biological mothers with at least one child born exposed to the virus. Semi-structured interviews were used for data collection. Analysis of the testimonials determined the categories: guilt and fear of giving birth to a child with HIV, discrimination and concealment of having HIV, child overprotection, lack of family support, and religiosity as a way of coping. The social representations of the women was an organization of meanings that acted as a system for interpreting reality, governing the relations with the physical and social environment, thus determining behaviors and practices. Furthermore, there is a need for skilled health care and a social network of support for promoting health.

Descriptors: VIH; Women's Health; Nursing Care.

\section{RESUMEN}

Estudio descriptivo, cualitativo, objetivando identificar las representaciones sociales de la maternidad en mujeres que engendran hijos expuestos al virus de inmunodeficiencia humana (HIV). Investigación realizada entre febrero y marzo de 2011, en hospital de referencia en atención de personas con HIV, incluyendo a diez madres biológicas con al menos un hijo nacido expuesto al virus. Datos recolectados por entrevista semiestructurada. El análisis de testimonios determinó las categorías: culpa y miedo de engendrar un hijo portador de HIV; discriminación y ocultamiento de portar HIV; sobreprotección del hijo; falta de apoyo familiar; religiosidad como modo de afrontamiento. Las representaciones sociales de las mujeres constituyeron una organización de significados que funcionó como sistema de interpretación de la realidad, dirigiendo las relaciones con el medio físico y social, determinando comportamientos y prácticas. Además, existe necesidad de atención calificada en salud y red social de apoyo para promoción de la salud.

Descriptores: HIV; Salud de la Mujer; Atención de Enfermería. 


\section{INTRODUÇÃO}

A Síndrome da Imunodeficiência Adquirida (aids) representa um sério problema de saúde pública, caracterizando-se como uma epidemia global $^{(1)}$. A infecção pelo Vírus da Imunodeficiência Humana (HIV), inicialmente restrita aos indivíduos do sexo masculino e usuários de drogas intravenosas, sofreu mudanças ao longo do tempo, ocasionando a disseminação entre o sexo feminino, principalmente, através da transmissão heterossexual $^{(2)}$. Este fato culminou no nascimento de crianças expostas ao HIV e famílias inteiras convivendo com o vírus ${ }^{(3)}$.

Nesse contexto, a infecção pelo HIV é uma problemática de grande magnitude, representando um desafio, no referente à transmissibilidade do vírus e aos prejuízos que causa aos portadores. Ademais, o aumento do número de mulheres com HIV em idade reprodutiva, reforça a necessidade de estudos sobre a temática, visto que podem contribuir para uma assistência em saúde direcionada aos problemas existentes ${ }^{(3-4)}$.

As mulheres que se descobrem portadoras do HIV na gestação ou que já têm conhecimento prévio do diagnóstico, vivenciam momentos de incerteza diante do risco de transmissão do vírus ao filho. Essa condição pode gerar mudanças marcantes na experiência da gestação e da maternidade ${ }^{(3-5)}$. Além disso, a concepção que as pessoas têm em relação à aids não se restringe a conhecimentos biomédicos acerca da infecção, mas incluem diferentes possibilidades que são as construções sociais da doença, representadas por forte estigma, relacionado às crenças tradicionais sobre a natureza moral da saúde, da enfermidade e do sofrimento humano ${ }^{(6)}$.

Confirmando esses aspectos, pesquisas mostram que as mulheres que vivem com HIV diferem das soronegativas para o vírus, pois têm aumento da reatividade emocional negativa e pontuações desfavoráveis em escalas que analisam as relações sociais e a qualidade de vida durante a gravidez e puerpério $^{(7-8)}$. Ademais, a presença generalizada de estigma relacionado ao HIV ameaça a experiência das mulheres no que se refere à gravidez e aos cuidados com a criança, pois aumenta a sua sensação de ansiedade e vulnerabilidade ${ }^{(8-9)}$.

Nesse contexto, a criança que nasce exposta ao HIV também está em processo de crescimento e desenvolvimento, necessitando ter acesso à educação, ao lazer, à saúde, além de diferentes tipos de relações humanas para a construção de sua identidade. No entanto, constata-se que os filhos de mães com HIV têm uma imagem diferenciada, a qual pode resultar em uma condição de vida atípica, influenciando negativamente no desenvolvimento físico, mental e de convivência com outros indivíduos ${ }^{(4-5,10)}$.

A reflexão sobre os aspectos biopsicossociais do HIV/aids revela informações importantes para as práticas de promoção da saúde, em particular no campo da enfermagem, principalmente, quando observamos que não é somente o indivíduo com HIV que sofre com a infecção, mas também seus familiares e outras pessoas de seu convívio. Observa-se que as mulheres expressam uma visão fatalista da infecção pelo HIV, sentindo-se impotentes para se proteger. O impacto do estigma relaciona-se com a culpa e a vergonha, questões que envolvem a divulgação do diagnóstico e as preocupações com o futuro ${ }^{(9-11)}$.

A assistência em saúde para pessoas com HIV/aids deve ser especializada, de forma que os aspectos que permeiam a vida desses indivíduos e que influenciam na saúde devem ser conhecidos. O estigma relacionado à doença interfere no bem-estar dos acometidos pelo HIV, na convivência social e até mesmo no atendimento em saúde. Assim, as pesquisas que analisam esses aspectos podem orientar a concepção de intervenções focadas em aumentar o acesso aos cuidados de saúde, reforçar o apoio social e a saúde emocional.

A vivência da doença não é advinda unicamente da infecção em si, mas ainda da interpretação da mesma pelo indivíduo. Portanto, é a partir desta interpretação, que as pessoas com HIV/aids atribuirão sentido à enfermidade, buscando um sentido para a vida. Por isso, apóia-se a efetivação de pesquisas na esfera da representação social do HIV, pois podem identificar os mecanismos pelos quais as pessoas estabelecem o significado deste acontecimento em suas realidades diárias $^{(10-11)}$.

Diante do exposto e considerando o aumento do número de casos de mulheres com HIV/aids ${ }^{(1-4)}$, teve-se por objetivo identificar as representações sociais da maternidade de mulheres que geram filhos expostos ao HIV. O conhecimento de aspectos do processo de maternidade dessas mulheres contribui para o desenvolvimento de estratégias que podem promover melhor qualidade de vida.

\section{METODOLOGIA}

Trata-se de um estudo descritivo e de abordagem qualitativa, realizado no ambulatório de um hospital de referência no atendimento a pessoas com HIV/aids, em Fortaleza, Ceará, Brasil. 
Considerando que a aids não representa apenas uma síndrome, mas um fenômeno social ${ }^{(1)}$ com impacto em todos os aspectos que envolvem a vida do indivíduo com HIV/aids, foi utilizado como referencial teórico para o estudo, a Teoria das Representações Sociais ${ }^{(12)}$. Serge Moscovici afirma que as representações sociais são um conjunto de conceitos, proposições e explicações originadas na vida cotidiana no curso de comunicações interpessoais. Esta teoria relaciona pessoas, símbolos e condutas, oriundas da experiência de cada ser humano, e de acordo com a ideologia da sociedade da qual ele faz parte ${ }^{(12)}$.

A investigação das representações sociais da maternidade de mulheres que geram filhos expostos ao HIV revela experiências e informações, ao mesmo tempo em que remete a um conhecimento particular acerca do fenômeno, o qual é elaborado a partir das experiências de vida dos indivíduos, em um determinado contexto sociocultural. Assim, o conjunto organizado de informações, atitudes e crenças que um indivíduo ou um grupo elabora a propósito de um objeto, de uma situação, ou de um conceito, apresenta-se, portanto, como uma visão subjetiva e social da realidade.

Os critérios de inclusão da pesquisa foi ser mãe biológica de pelo menos um filho nascido exposto ao HIV, ter idade igual ou superior a 18 anos, com assinatura prévia do Termo de Consentimento Livre e Esclarecido (TCLE). Como critério de exclusão adotou-se a presença de doença mental ou qualquer outra condição que interferisse nas respostas aos quesitos elaborados pelo pesquisador.

Integraram-se ao estudo 10 mães que vivem com HIV. O número de sujeitos da pesquisa foi determinado durante 0 desenvolvimento das entrevistas por saturação(13), ou seja, o estudo foi encerrado à medida em que os depoimentos e experiências das mães foram se repetindo.

A coleta de dados ocorreu nos meses de fevereiro a março de 2011, utilizando-se um roteiro semiestruturado norteador da entrevista, o qual contemplava a caracterização sociodemográfica da mãe e do filho e fazia o seguinte questionamento: "Fale-me sobre o processo de maternidade na vigência do HIV". Todas as entrevistas foram áudio-gravadas em ambiente privativo e tiveram duração média de 45 minutos.

Após coleta de dados, os depoimentos das mães foram transcritos para leitura e exploração dos achados. Para o tratamento das informações obtidas, adotou-se a análise de conteúdo por categorias temáticas ${ }^{(13)}$, tendo como referencial a Teoria das Representações Sociais ${ }^{(12)}$.
O procedimento foi composto por três fases: 1 . Organização e sistematização das ideias; 2. Exploração do material, correspondente à transformação sistemática dos dados brutos do texto, por recorte, agregação e enumeração; e 3. Tratamento dos resultados, inferência e interpretação do material à luz do referencial teórico das representações sociais.

A partir dos procedimentos de análise foram identificadas as categorias: culpa e o medo de gerar um filho portador do HIV; discriminação e ocultamento de ser portador do HIV; superproteção do filho; falta de apoio familiar; religiosidade como forma de enfrentamento.

O projeto foi submetido ao Comitê de Ética, de acordo com a Resolução n 466/2012 do Conselho Nacional de Saúde sobre pesquisas que envolvem seres humanos, sendo aprovado sob protocolo $n^{\circ}$ 035.04.10 em 30/07/2010. Todas as mães assinaram o TCLE. Para preservar a identidade das participantes, utilizou-se a letra "E" (de entrevistada) sucedida por algarismos arábicos conforme a ordem de registro.

\section{RESULTADOS E DISCUSSÃO}

A idade das mães variou de 18 a 38 anos, enquanto a das crianças situou-se entre seis meses e três anos. Quanto ao sexo das crianças, prevaleceu o masculino. Já a renda familiar mencionada pelas mães alternou-se entre $R \$ 545,00$ e $R \$ 2.180,00$. Em relação à escolaridade, duas mães eram analfabetas, duas tinham apenas ensino fundamental incompleto, quatro possuíam o ensino médio incompleto e somente duas concluíram o ensino médio. Estes achados reafirmam resultados de outros estudos, nos quais o HIV acomete, principalmente, mulheres em idade fértil e com baixo nível escolar ${ }^{(1-5)}$.

Os depoimentos revelaram que a maternidade das portadoras de HIV é cercada de preconceito, falta de apoio familiar, isolamento social, medo da morte e da possível contaminação da criança. Estes achados são a representação social da aids, evidenciando a complexidade da doença e confirmando que ela não pode ser percebida apenas como um problema fisiológico, mas também como um problema existencial, por interferir na maneira como as pessoas se percebem e são percebidas no mundo ${ }^{(6)}$.

\section{Culpa e o medo de gerar um filho portador do HIV}

Em decorrência da preocupação com a possibilidade de contaminação da criança, percebe-se a culpa e o 
medo vivenciado pelas mães quanto ao diagnóstico do bebê.

[...] ainda não fiz o exame dele, tenho medo dele ter também. Minha preocupação é mais com ele, e não comigo, é que ele é tão pequenininho, não sabe de nada ainda. Se ele tiver o vírus serei a culpada (E4).

O processo de maternidade das mães com HIV/aids é uma situação de vulnerabilidade, agravada pelo sentimento de culpa, ansiedade e incerteza em virtude da exposição do filho ao vírus. Pesquisas mostram que a culpa advém do envolvimento de um ser inocente na infecção pelo $\operatorname{HIV}^{(4-5,7,14)}$. O medo de que outras pessoas a considerem culpada pela infecção do filho ocorre, sendo uma forma de representação social da problemática que permeia o HIV/aids.

Quando a infecção pelo HIV é descoberta durante a gestação, as mulheres seguem medidas profiláticas para evitar a transmissão vertical do vírus. Evidencia-se o alívio após a confirmação do diagnóstico negativo da criança, condição interpretada pelas mães como uma forma de recompensa e corporificação de um desejo bem presente durante a gravidez: a saúde da criança representada pela sorologia negativa para o HIV.

Meu bebê é soronegativo, ele tem um ano e nove meses. Eu descobri durante a gravidez e fiz o tratamento. Fiquei muito feliz porque ele não tem o vírus (E10).

As mães sentem culpa quando não sabem a sorologia anti-HIV do filho. Já as mulheres seguras da soronegatividade da criança para o vírus referem alívio, porquanto haviam realizado a terapia para a prevenção da transmissão vertical.

Tenho culpa sim, agora que passou mais, mas no começo fiquei desesperada, me deu vontade de fazer aborto. Mas graças a Deus, as pessoas que sabem ficaram comigo, me deram apoio, o médico também, tanto daqui quanto da maternidade, eu fiz o tratamento direitinho, eles me explicaram tudo, então, foi me confortando mais (E7).

Descobri na gravidez, no pré-natal. Eu fiz o tratamento na gravidez. Agora não me sinto mais culpada (E9).

De acordo com estas informações, a principal angústia vivenciada pelas mulheres é o medo de contaminarem 0 filho ${ }^{(4-5,7-8,14)}$. Deve-se orientar a paciente quanto à doença, as medidas profiláticas da transmissão vertical do vírus e o risco ao qual a criança está exposta. É preciso garantir o acesso das mães à terapia antirretroviral na gestação, parto e puerpério, sobretudo por ser um direito das mães soropositivas para o $\mathrm{HIV}^{(3-4)}$.

\section{Discriminação e ocultamento de ser portador do HIV}

Algumas mães optam por ocultar o diagnóstico de soropositividade para o HIV, no intuito de evitar que a exposição da criança ao vírus seja descoberta. O receio de revelar o diagnóstico advém do temor quanto ao julgamento social.

Ele está na creche, as pessoas não sabem que eu sou portadora, só quem sabe é o pessoal do posto, nem minha família sabe, eu não gosto de sair contando. Alguns entendem, outros não (E1).

Só quem sabe são as pessoas mais próximas, minha mãe, minha avó e minha tia [...] (E5).

Preconceito eu não sofri, porque eu nunca contei pra ninguém, no meu trabalho ninguém sabe (E3).

Não sofri preconceito não. Ninguém sabe [...] ninguém precisa ficar sabendo, porque eu não quero falar (E9).

Por ser uma doença ligada a comportamentos promíscuos, tais como o homossexualismo, o uso de drogas e promiscuidade, o diagnóstico não é revelado a todos devido ao medo da estigmatização e preconceito $^{(4,7,9-10)}$. A ocultação pode ser acompanhada de dificuldades durante a gestação e no período de definição da sorologia anti-HIV da criança, sendo um momento de vulnerabilidade para as mulheres que estão desprovidas de apoio familiar e social ${ }^{(14)}$.

O temor do preconceito se estende à criança, por medo das pessoas a rejeitarem ou tratá-la de forma diferente em espaços sociais, como creches e escolas. $\mathrm{Na}$ tentativa de resguardar os filhos, muitas mães os isolam do contato com outras crianças e ocultam a exposição ao HIV. Revelar o diagnóstico leva à possibilidade da vivência de polaridades divergentes, ou seja, solidariedade, apoio, compreensão, críticas negativas, estigmas e discriminação social ${ }^{(7,14-15)}$. Assim, a revelação do diagnóstico pode ser traumatizante, pois gera a sensação de medo do abandono pelos familiares,

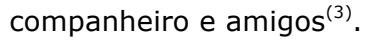

Apesar desses relatos, muitas vezes, as situações de preconceito não podem ser evitadas. Na fala seguinte é relatado o preconceito dirigido à mãe e à criança por 
parte dos próprios familiares, o qual estava relacionado ao desconhecimento das formas de transmissão do HIV:

Minha família sabe, se afastaram. Colocaram-me para fora de casa, se eu fosse comer uma coisa, minhas coisas eram todas separadas [...] Tudo com nojo de mim e do bebê também (E2).

A discriminação sofrida por estes pacientes é lamentável, revelando a necessidade de avanço quanto à educação da população no tocante à infecção pelo vírus. Considera-se que a pessoa com HIV/aids deve ser vista por todos indistintamente, assim como a criança nascida exposta ao HIV tem o direito de ser cuidada de maneira igualitária e receber tratamento livre de preconceito.

Neste âmbito, as campanhas educativas divulgadas em nível nacional ou local, pelas organizações governamentais ou não, além de orientar os profissionais de saúde, devem abranger a sociedade como um todo, pois contribuirá para a não discriminação das pessoas que vivem com o vírus ${ }^{(3,7-8,10)}$.

Uma das entrevistadas mencionou ter vivenciado preconceito por parte de um profissional da saúde. Tal fato demonstra que a equipe de saúde responsável pela assistência às pessoas com HIV, nem sempre está preparada para prover acolhimento satisfatório. Como observado, é comum o relato de pouca atenção dos serviços de saúde para as relações dialógicas favoráveis:

Sofri preconceito. Quando eu vinha lá da sala de parto, eu vinha pra enfermaria, aí a enfermeira perguntou: ela vai ficar aqui junto com as outras? Ela ia me colocar no último quarto, mas não colocou, ela me deixou na mesma enfermaria (E8).

Em face disso, estudos mostram que muitos profissionais que atendem aos portadores de HIV/aids não possuem conhecimento ou qualificação na área ${ }^{(3,5)}$. O tratamento destes pacientes deve ir além da administração de medicamentos, se estendendo a um cuidado físico e emocional $^{(1,3,9)}$.

Assim, enfatiza-se a importância de sensibilizar e preparar os profissionais de saúde, para que compreendam o impacto da soropositividade para o HIV na vida dos portadores, mediante o aconselhamento centrado no diálogo, na escuta, na empatia e acolhimento. Ademais, o desrespeito aos aspectos éticos implicados no atendimento às pessoas com HIV/aids pode afetar a saúde física e emocional destes, os quais já se encontram em situação vulnerável, esperando do profissional uma assistência acolhedora e de qualidade.

\section{Superproteção do filho}

A atitude de superproteção do filho está presente no cotidiano das mães e configura-se como uma estratégia de atenuação da culpa por expô-lo ao vírus. Mesmo sabendo do diagnóstico soronegativo da criança para o HIV, algumas mães reforçam os cuidados com a saúde do filho, com o intuito de prevenir o adoecimento. Notase também uma preocupação com os instrumentos perfurocortantes utilizados pelos adultos soropositivos para o HIV, para evitar a exposição da criança ao vírus.

Tenho um cuidado especial com ela pra ela não adoecer (E3).

Eu trato ele normal, mas a tesoura é separada, pra ele não entrar em contato com o HIV (E5).

[...] com adoecer eu tenho mais cuidado, qualquer gripezinha eu já fico com medo, mesmo ele não tendo o HIV (E10).

Observa-se que alguns depoimentos são ambivalentes, ora a mãe relata considerar a criança nascida exposta ao HIV como normal, não restringindo a interação desta com outras crianças; ora relata reforçar os cuidados para prevenir a eclosão de doenças, como exposto a seguir:

Eu não o separo das outras crianças, eu o acho normal, mas poeira eu já tenho cuidado, mas eu o deixo correr e brincar normalmente (E4).

[...] brincadeira, ela brinca normal, só tenho medo quando ela tem algum problema de saúde, mas no resto ela tem uma vida normal (E7).

As mães que vivem com HIV são cercadas por questionamentos, quanto ao tempo de sobrevivência delas, evidenciando-se o medo de não poder criar os filhos ou de vê-los morrer. Ao mesmo tempo, a doença desencadeia um esforço maior para lutar pela vida, para viver e poder criar os filhos.

Eu tenho medo de perder ele, tenho medo de morrer também. Tenho medo dele e da minha outra filha viver sozinha sofrendo [...] (E2).

Tenho medo da morte, eu tenho pânico se acontecer alguma coisa comigo. Como ela vai ficar? Tenho que fazer o que posso por ela, tenho que continuar (E7). 
Tal como no presente estudo, outras pesquisas também observam que as mães com HIV/aids desenvolvem um sentimento de superproteção em relação ao filho, dispensando mais cuidados do que de costume. O medo da contaminação do filho pelo vírus e de que ele tenha mais chances de adquirir outras doenças também foi expresso pelas mães ${ }^{(3,15-16)}$.

A superproteção é uma tentativa de recompensar a exposição da criança ao HIV, levando as mães a lutarem exaustivamente pelo bem-estar e direitos dos filhos ${ }^{(4-5,15-}$ 16). Esta realidade se reflete no aumento dos cuidados à criança e no cumprimento rigoroso das consultas, exames e administração de medicamentos ${ }^{(5)}$. Ressaltamos ainda que a socialização com outras crianças faz parte de uma vida comum. Ao superproteger a criança por medo do preconceito, a mãe pode desencadear-lhe $o$ isolamento que pode ocasionar $o$ consequente prejuízo no desenvolvimento desta ${ }^{(16)}$.

Apesar da evolução do tratamento para a infecção pelo HIV e aids, ainda existe a associação entre a doença e a morte. Isso porque, na sociedade, a imagem da epidemia foi construída a partir de pessoas que já estavam em estágio avançado da doença, ressaltando a representação social da aids como indivíduos debilitados, sofridos e aguardando a morte ${ }^{(6)}$.

Porém, com o avanço dos fármacos antirretrovirais, tornou-se possível prolongar a vida com a infecção, sem se manifestarem os sintomas da aids e as doenças associadas. Logo, a aids vem se transformando em mais uma doença crônica, que embora limite a vida dos portadores em alguns aspectos, não significa ser deficiente ou necessariamente morrer ${ }^{(17)}$. Nesta perspectiva, as pessoas que vivem com HIV devem ser informadas sobre a cronicidade da doença, e de que os anos de vida podem ser prolongados mediante a satisfatória adesão aos fármacos antirretrovirais e de outros cuidados específicos.

\section{Falta de apoio familiar}

$\mathrm{Na}$ maioria dos depoimentos, as entrevistadas afirmaram viverem sozinhas e não contarem com o apoio da família e do parceiro. Em alguns casos, a relação com o parceiro é instável e as ameaças de abandono são frequentes. Em determinadas situações, o abandono familiar é total, e a solidão fica explícita como nas falas a seguir:

[...] o pai dele me abandonou, disse que era pra eu abortar (E1).
[...] ninguém cuida de mim, não tenho apoio da família, sou sozinha no mundo [...] (E2).

Segundo constataram-se, apenas duas mulheres afirmaram ter recebido apoio familiar:

Meus familiares não ficaram tristes, não tiveram preconceito [...] são loucos por ela [...] (E7).

Minha família sabe, mas meus amigos não. Assim na frente da gente não sei, na nossa frente é totalmente diferente, é uma boa, não sei pelas costas, mas eu acho que não, minha família não é assim não (se referindo ao fato da família não ter preconceito) (E8).

Dessa forma, observa-se a preocupação das mães em relação ao futuro e à falta de apoio familiar, referindo-se o medo da morte e de não ter com quem deixar os filhos em caso de falecimento ${ }^{(4,7,16)}$. De modo geral, a instabilidade na relação das mulheres com o pai do bebê é frequente. Em algumas situações, o diagnóstico é omitido e as mulheres não têm apoio do parceiro e da família. Como mostrado em outra pesquisa, isso torna a vivência da soropositividade para o HIV e a criação da criança mais difícil e solitária(4-5,7-8).

Estudos confirmam que as mulheres que contam com o apoio do companheiro e da família desde as consultas pré-natais demonstram maior aderência ao tratamento para prevenir a transmissão vertical, além de maior suporte emocional ${ }^{(17-20)}$. Por sua vez, as crianças necessitam da família, mesmo que não lhes sejam dispensados os cuidados necessários, a vivência em um ambiente familiar ajuda no enfrentamento da infecção pelo $\mathrm{HIV}^{(16,21)}$.

Pesquisas ainda mostram a importância do apoio familiar para que a pessoa com HIV/aids tenha adesão adequada ao tratamento antirretroviral ${ }^{(22)}$, reduza a ocorrência de depressão e melhore a saúde mental ${ }^{(23)}$. Para tanto, torna-se necessário a incorporação de aconselhamento e apoio à família nos serviços de saúde direcionados aos indivíduos com HIV/aids, com foco especial em amenizar a interação negativa e reforçar o apoio emocional ${ }^{(22-23)}$.

\section{Religiosidade como forma de enfrentamento}

Para a maioria das mães, a religião significou uma forma de suporte social e auxílio no enfrentamento da doença, por proporcionar emoções positivas e sentimentos de conforto, propiciando apoio espiritual e emocional, como descrito a seguir: 
Eu sobrevivi porque Deus quis (E1).

Eu não posso conversar com ninguém, eu converso só com Deus (E2).

Eu oro muito pra Deus, pra que dê tudo certo na vida dela (se referindo à filha). A religião me ajuda muito, me dá mais força (E3).

Conforme constatado, as práticas religiosas são utilizadas como método de enfrentamento e reforçam a esperança de que o filho cresça sadio. Como observado em outra pesquisa ${ }^{(13)}$, a religião facilita a aceitação da doença, propicia força e sensação de controle, reduz o medo da morte e a culpa, além de ajudar no apoio social advindo de outras pessoas.

Estudos ainda confirmam que a adesão a alguma religião está fortemente ligada à adaptação psicológica à infecção pelo HIV, bem como a resultados psicológicos satisfatórios, como a redução da ansiedade e depressão, além de melhor qualidade de vida e aumento da adesão à terapia antirretroviral ${ }^{(24-25)}$.

\section{CONCLUSÃO}

O estudo mostrou características da maternidade de mães que geram filhos expostos ao HIV, identificando as representações sociais da doença no contexto familiar e social. As categorias formuladas envolveram a culpa e o medo de gerar um filho portador do HIV, a discriminação e ocultamento de ser portador do HIV, a superproteção do filho, a falta de apoio familiar e a religiosidade como forma de enfrentamento. A partir desses achados, constatou-se o estigma, o preconceito, a ausência de apoio da família e dos amigos, o medo da morte e da contaminação da criança, dentre outros aspectos que podem influenciar negativamente a qualidade de vida das mães e filhos.

A maioria das pesquisas sobre HIV/aids destacam os aspectos epidemiológicos, biológicos e de tratamento os quais são analisados a partir da ótica quantitativa. No entanto, os estudos que tratam dos aspectos psicológicos e sociais, trabalham na perspectiva da percepção do indivíduo sobre ele mesmo e em relação ao meio

\section{REFERÊNCIAS}

1. Gomes AMT, Silva EMP, Oliveira DC. Social representations of aids and their quotidian interfaces for people living with HIV. Rev. Latino-Am Enfermagem. 2011;19(3):485-92.

2. Cunha GH, Galvão MTG. Nursing diagnoses in patients with Human Immunodeficiency Virus/Acquired Immunodeficiency Syndrome in outpatient care. Acta Paul Enferm. 2010;23(4):52632. externo, necessitando, muitas vezes, de uma teoria para melhor entendimento dos achados.

Diante disso, os resultados desse estudo ao explorar as representações sociais da maternidade de mulheres com HIV/aids, contataram que a representação social pode ser vista como uma organização de significados que funciona como um sistema de interpretação da realidade, capaz de reger as relações dos indivíduos com o seu meio físico e social, além de determinar comportamentos e práticas. Esses aspectos retratam a necessidade de uma visão holística direcionada às mães com HIV/aids e ao processo saúde-doença, visto que a aids não é somente uma doença física, mas que se integra a todos os aspectos do viver das pessoas atingidas.

O objetivo do estudo foi contemplado, mas durante a realização da pesquisa, percebeu-se que seria importante conhecer a percepção dos outros sujeitos indiretamente envolvidos no processo de maternidades das mulheres com HIV/aids, como os parceiros, familiares e profissionais de saúde, a fim de se entender os comportamentos inadequados, que na maioria das vezes, decorrem da falta de conhecimento acerca da doença e do tratamento. Isso pode representar indiretamente uma limitação do estudo, além de algo a ser abordado em pesquisas futuras.

Quanto a isso, a educação permanente em serviço e a utilização de estratégias de educação em saúde poderiam ajudar os profissionais e as pessoas que cuidam das mães que vivenciam a transmissão vertical do HIV, a terem uma vida mais plena e sem preconceito.

Apesar dos vários estudos realizados sobre a temática, ainda parece ser uma lacuna da literatura, a investigação das circunstâncias de privações familiares e que tipo de apoio em diversos setores da vida necessitam, tanto as crianças portadoras do vírus, quanto suas mães e familiares. Pesquisas sobre esses aspectos podem produzir novas evidências que possam melhorar a qualidade da atenção em saúde, especialmente, relacionadas às formas de inclusão social, como por exemplo, o incentivo aos grupos de apoio às mulheres com filhos nascidos expostos ao HIV, mediante a inserção dos parceiros, familiares e comunidade.

3. Ministério da Saúde. Secretaria Executiva de Vigilância em Saúde. Coordenação Nacional de DST e aids. Recomendações para profilaxia da transmissão vertical do HIV e terapia antirretroviral em gestantes. Brasília: Ministério da Saúde (BR); 2010.

4. Galvão MTG, Cunha GH, Machado MMT. Dilemas e conflitos de ser mãe na vigência do HIV/aids. Rev Bras Enferm. $2010 ; 63(3): 371-6$. 
5. Gonçalves TR, Piccinini CA. Experiência da maternidade no contexto do HIV/aids aos três meses de vida do bebê. Psic. Teor. e Pesq. 2008;24(4):459-70.

6. Formozo GA, Oliveira DC. Representações sociais do cuidado prestado aos pacientes soropositivos ao HIV. Rev Bras Enferm. 2010;63(2):230-7.

7. Pereira M, Canavarro MC. Quality of life and emotional distress among HIV-positive women during transition to motherhood. Span J Psychol. 2012;15(3):1303-14.

8. Kelly C, Alderdice F, Lohan M, Spence D. 'Every pregnant woman needs a midwife' - the experiences of HIV affected women in maternity care. Midwifery. 2013;29(2):132-8.

9. Byamugisha R, Tumwine JK, Semiyaga N, Tylleskar T. Determinants of male involvement in the prevention of motherto-child transmission of HIV programme in Eastern Uganda: a cross-sectional survey. Reprod Health. 2010;7(12):1-9.

10. Gomes AMT, Barbosa BFS, Oliveira DC, Wolter RMCP, Silva MVG. As representações sociais de enfermeiros sobre a criança soropositiva para HIV: interface com o cuidar. Rev enferm UERJ. 2011;19(1):14-9.

11. Nyamathi AM, William RR, Ganguly KK, Sinha S, Heravian A, Albarrán CR, Thomas A, Greengold B, Ekstrand M, Ramakrishna $P$, Rao PR. Perceptions of women living with aids in rural India related to the engagement of HIV-trained accredited social health activists for care and support. J HIV AIDS Soc Serv.

2010;9(4):385-404.

12. Moscovici S. Representações sociais: investigações em psicologia social. Petrópolis: Vozes; 2003.

13. Bardin L. Análise de conteúdo. Lisboa: Persona; 2009. 14. Araújo MAL, Queiroz FPA, Melo SP, Silveira CB, Silva RM. Gestantes portadoras do HIV: enfrentamento e percepção de uma nova realidade. Cienc Cuid Saúde. 2008;7(2): 216-23. 15. Vieira M, Padilha MI, Santos EKA. História de vida - mãe e filho soropositivo para o HIV. Texto Contexto Enferm. 2009;18(1):33-40.

16. Silva RAR, Rocha VM, Davim RMB, Torres GV. Formas de enfrentamento da aids: opinião de mães de crianças soropositivas. Rev Latino-Am Enfermagem. 2008;16(2):260-5. 17. Medeiros HMF, Motta MGC. Existir de crianças com aids em casa de apoio: compreensões à luz da enfermagem humanística. Rev Gaúcha Enferm. 2008;29(3):400-7.

18. Freitas HMB, Backes DS, Pereira ADA, Ferreira CLL, Souza $\mathrm{MHT}$, Marchiori MRCT, et al. Understanding the family member of a child affected by Human Immunodeficiency Virus/Acquired Immunodeficiency Syndrome, from the perspective of complexity. Acta Paul Enferm. 2010;23(5):597-602. 19. Msuya SE, Mbizyo EM, Hussain A, Uriyo J, Sam NE, StrayPedersen B. Low male partner participation in antenatal HIV counselling and testing in northern Tanzania: implications for preventive programs. AIDS Care. 2008;20(6):700-9. 20. Feitosa JA, Coriolano MWL, Alencar EN, Lima LS. Aconselhamento do pré-teste anti-HIV no pré-natal: percepções da gestante. Rev enferm UERJ. 2010;18(4):559-64.

21. Felismino HP, Costa SFG, Soares MJGO. Direitos e deveres de pessoas com HIV/aids no âmbito da saúde: um enfoque bioético. Rev. Eletr. Enf. [Internet]. 2008 [cited 2012 jan 20];10(1):8799. Available from:

http://www.fen.ufg.br/revista/v10/n1/v10n1a08.htm

22. Wouters E, Masquillier C, Ponnet K, le Roux Booysen F. A peer adherence support intervention to improve the antiretroviral treatment outcomes of HIV patients in South Africa: The moderating role of family dynamics. Soc Sci Med.

2014;113C:145-53.

23. Amiya RM, Poudel KC, Poudel-Tandukar K, Pandey BD, Jimba M. Perceived family support, depression, and suicidal ideation among people living with HIV/aids: a cross-sectional study in the Kathmandu Valley, Nepal. PLoS One. 2014;9(3):e90959.

24. Dalmida SG, Koenig HG, Holstad MM, Wirani MM. The psychological well-being of people living with HIV/aids and the role of religious coping and social support. Int J Psychiatry Med. 2013;46(1):57-83.

25. Vyas KJ, Limneos J, Qin H, Mathews WC. Assessing baseline religious practices and beliefs to predict adherence to highly active antiretroviral therapy among HIV-infected persons. AIDS Care. $2014 ; 26(8): 983-7$.

Artigo recebido em 23/02/2013.

Aprovado para publicação em 02/06/2014.

Artigo publicado em 31/12/2014. 